\title{
Developing a Numerical Model for a Deep Open Pit
}

\author{
E.C.F. Hamman Anglogold Ashanti Australia Ltd, Australia
}

M.A. Coulthard M.A. Coulthard \& Associates, Australia

\begin{abstract}
Sunrise Dam Gold Mine consists of the Cleo open pit and extensive underground development from where the extraction of flat and steep dipping tabular orebodies have commenced in the western wall of the pit. The ultimate open-pit dimensions will be approximately $2100 \mathrm{~m}$ long, $1200 \mathrm{~m}$ wide and $440 \mathrm{~m}$ deep.

The pit is geotechnically demanding with mining exposing new challenges on each bench due to the varying lithologies and complex structural geology. In 2003, a detailed structural mapping programme was started to identify potential problematic mine-scale structures, and to evaluate the properties of the main joint sets observed in the pit. A number of strength testing programmes were completed each year to establish a rock mass property database.

The data from both these programmes formed the basis of the geotechnical model used to select the design sections to be analysed using numerical analysis techniques. Four design sections were selected for the western wall to evaluate the slope behaviour using the program UDEC. The UDEC models for each section incorporated an explicit representation of the major joint sets within the rock mass, and also treated the rock material strength via the Hoek-Brown criterion. Parametric studies were performed, considering two cases of joint friction angle and both upper and lower estimates for rock material UCS. Each model consisted of an equilibration of the pre-mining system, then excavation to the ultimate pit in three stages. Finally, rock and joint strengths were progressively reduced for the final stage of mining, to provide estimates of the factor of safety (FoS) of the west wall slope.
\end{abstract}

\section{Introduction}

Sunrise Dam Gold Mine is located beside Lake Carey, $730 \mathrm{~km} \mathrm{NE}$ of Perth, WA. The mine consists of the Cleo open pit and extensive underground development from where the extraction of flat and steep dipping tabular orebodies have commenced in the western wall of the pit. The ultimate open-pit dimensions will be approximately $2100 \mathrm{~m}$ long, $1200 \mathrm{~m}$ wide, and $440 \mathrm{~m}$ deep. Currently the pit is $360 \mathrm{~m}$ deep, with another $80 \mathrm{~m}$ to go in the Mega cutback over the next 12 months, before the final Northwall cutback starts.

Mineralisation was discovered in 1993 and contract mining commenced in 1996. Numerous staged cutbacks were done between 1997 and 1999. Planning commenced in 1999 for the ultimate open pit. From optimisation studies it was apparent that the final pit would be either a modest open pit of short life or a very large and deep open pit of around ten years life. The decision was made to mine a $460 \mathrm{~m}$ deep pit, to be known as the Mega Pit.

The Mega cutback was commenced in July 2000. It was characterised by initial mining of lake sediments (clays) and then saprolites, with a thin transitional band before reaching fresh rock at a depth of around $80 \mathrm{~m}$. Concurrent with the Mega cutback was the continued mining of ore from the CleoSW and Cleo Main pits until the Mega pit consumed these initial pits. In early 2002 a study was done on the possibility of a further cutback to the south and in July 2002 the Watu cutback was commenced. This first two months included mining part of the previously placed waste dump and then moved into mining a similar sequence of material types to the Mega cutback. 


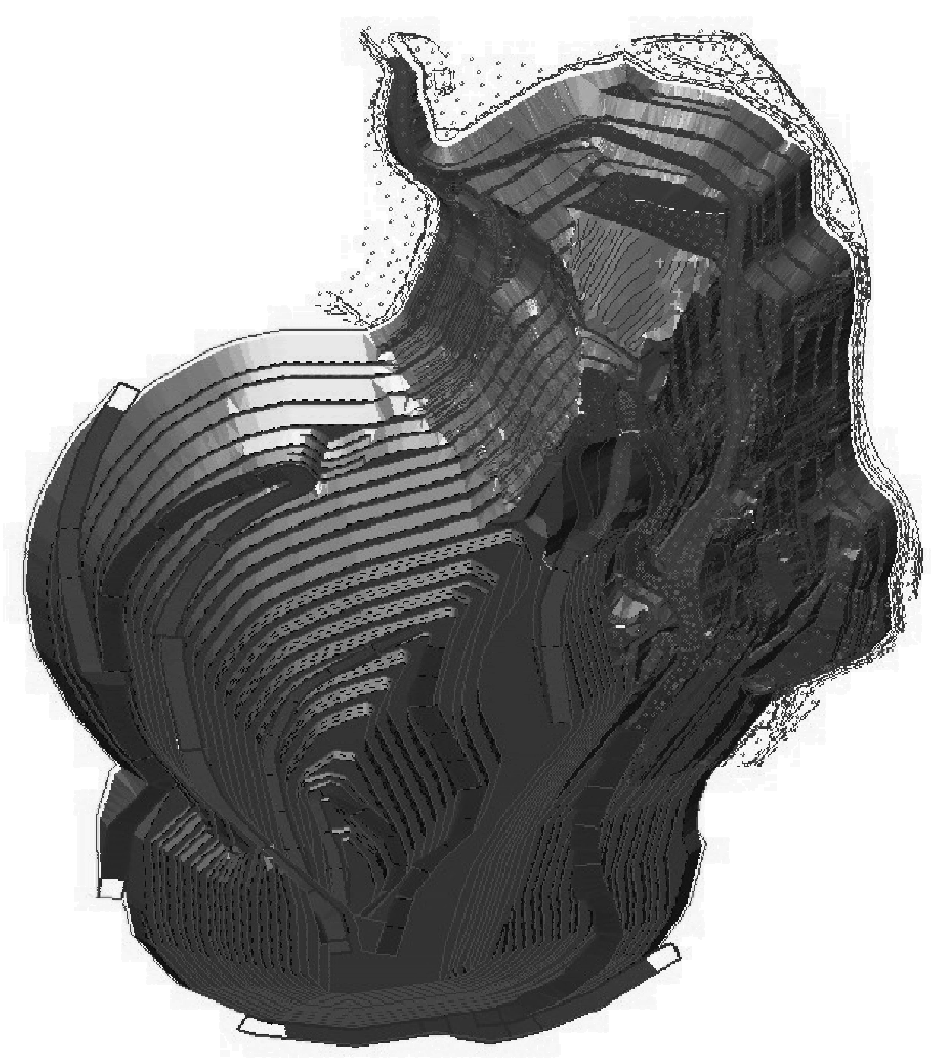

Figure 1 Sunrise Dam Gold Mine - view from the south

Underground operations started the first decline in October 2003. By May 2007, $150 \mathrm{mbcm}$ of material had been mined and the pit was $360 \mathrm{~m}$ deep, with another $80 \mathrm{~m}$ to mine to the ultimate $440 \mathrm{~m}$ depth by early 2008. Underground had by this stage completed $24 \mathrm{~km}$ of development and 700,000 tonnes of stoping down dip and along strike of open pit ore bodies. A final cutback will start in late 2007 on the northwest wall and is expected to take at least three years to complete.

As seen above, a number of cutbacks have already been mined with the final cutback starting late 2007. As the mine developed with each of these cutbacks, it required new designs for the proposed cutback final walls. Slope design is an iterative process and described by Lilly (2002) as follows:

- Collection of relevant geological and geotechnical data.

- Estimation of geotechnical design parameters.

- Identification of potential failure mechanisms.

- Slope stability assessment and engineering analysis.

- Slope design.

- Slope formation.

- Slope validation mapping and performance monitoring.

By feeding data from Step 7 back into the process as part of Step 1, the design parameters in Step 2 can be validated and/or changed as required for an existing or new design.

The following sections will summarise the geotechnical data obtained as the pit was mined, and discuss how it was used to develop a numerical model using the programme UDEC for the ultimate Mega pit. 


\section{Geotechnical data obtained during mining}

The pit is geotechnically demanding with mining exposing new challenges on each bench due to the varying lithologies and complex structural geology. Over the last ten years a substantial investment was made to understand the groundwater regime and structural domains as these two factors were found to be major contributors to slope stability.

A groundwater programme was put in place to facilitate dewatering of the weathered material and gain insight into the fresh rock groundwater regime, following a circular failure in a $60 \mathrm{~m}$ high slope in the Mega cutback through the thickest interval of transported lake clays in the southwest corner of the pit in April 2000.

On January 1st 2003, a significant failure occurred shortly after a blast, associated with the west dipping Placer and Margies shears. The failure occurred over a $60 \mathrm{~m}$ stack, causing major damage to the dewatering pump station. At this stage, mapping of structures was limited and no site based dedicated personnel were looking after the short and long-term geotechnical requirements of the mine. The failure hastened the appointment of a site based geotechnical engineer and the start of a detailed structural evaluation of the planned east and west walls to modify the pit slope design based on a geotechnical model. The following section briefly describes the geotechnical properties as currently understood.

\subsection{Geology}

The Cleo-Sunrise deposit is in the north-eastern part of the Eastern Goldfields Province of the Yilgarn Craton, Western Australia. The deposit stratigraphy consists of a shallowly NW-dipping Archaean sequence dominated by andesitic volcanogenic sedimentary rocks, andesitic volcanic rocks and magnetite shales (BIF sensu lato). The stratigraphy forms a broadly fining upwards sequence of volcaniclasti sedimentary rocks. Minor units include quartz diorite sills, ultramafic and two types of felsic porphyry.

The stratigraphy is interpreted to have been structurally replicated by movement on the shallow dipping Sunrise Shear Zone (SSZ) and Cleo Upper Shear Zone (CSZ) (Figure 2).

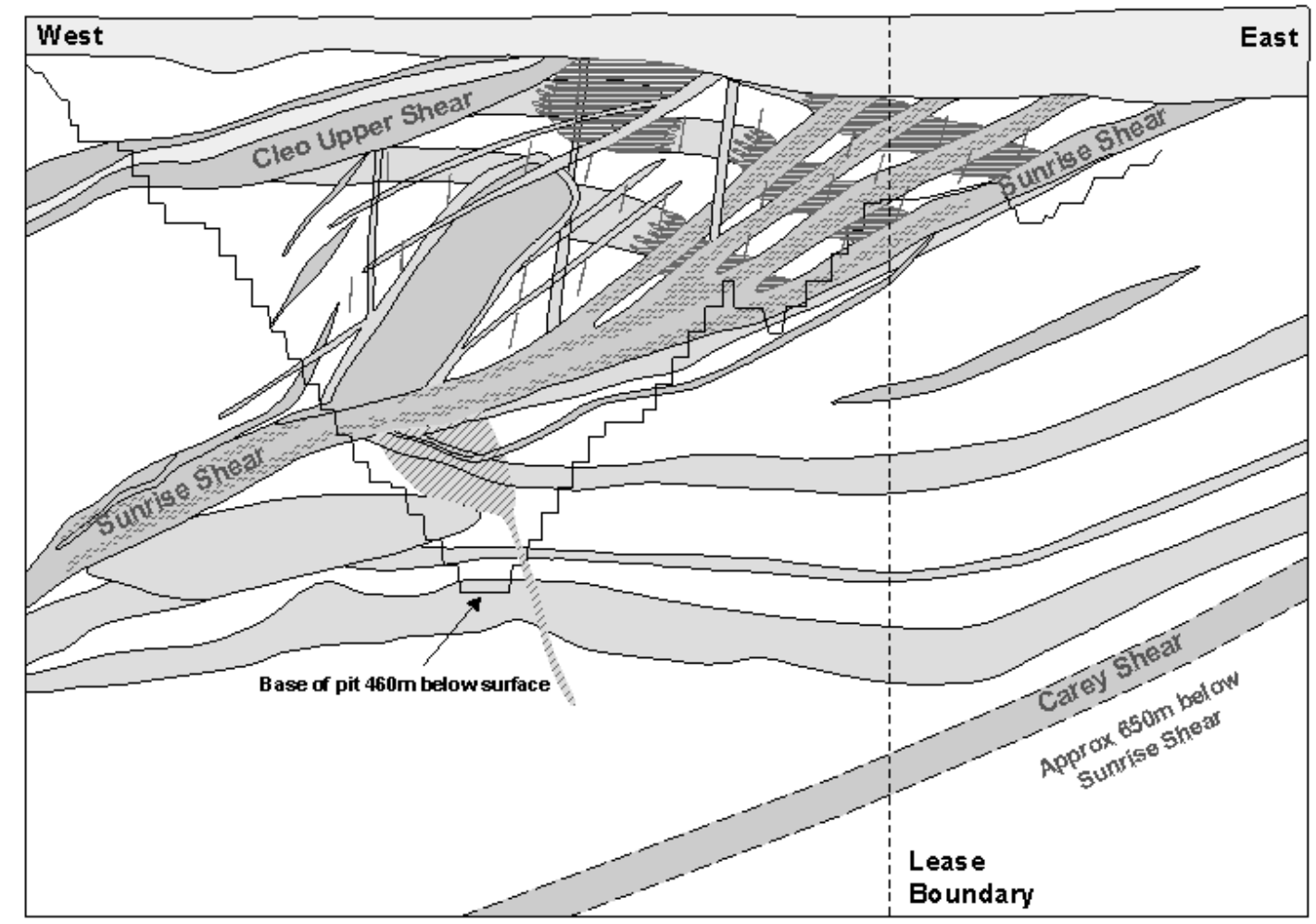

Figure 2 Schematic geologic section of the Cleo - Sunrise Deposit 
Transported sediments cover the deposit and are separated into two units, an Upper and a Lower Lake Sequence. The sediments lie above an unconformity that shows significant variation in relief.

Throughout the deposit a dominant SW to WSW orientation exists. This orientation includes the large ore bearing shear zones - Margies, Placer and Sunrise shears. Re-activation of these shears is evident throughout the deposit.

A set of flat north-west dipping, multibench-scale sericite altered shears and a flat north-east dipping set occur in the mafic hanging wall contact, which may be a result of localised stress changes resulting from the large mafic intrusion. In the immediate hanging wall zone (30-40 m wide) of the mafic unit, blocky rock mass characteristics exist. Flat lying, ENE dipping, sericite altered shears are prominent in the SE Mega pit interim wall mapping. The shears occur as thin structures $(10-30 \mathrm{~cm})$ with $20-200 \mathrm{~cm}$ wide alteration halos. A steep WSW oriented set of shears is prominent in the SE Mega pit along side the ENE dipping set (Fowers, 2005, 2006).

Mapping along the west wall revealed no major adversely orientated shears. The joint sets exposed were consistent on a stack scale and is summarised in Table 1.

Table 1 Properties of joints for all design sections in west wall

\begin{tabular}{ccccccll}
\hline Jointset & Dip & Dipdir & Length & Spacing & Friction & Cohesion & Description \\
\hline 1 & $33^{\circ} \pm 5^{\circ}$ & $15^{\circ} \pm 10^{\circ}$ & $5-10 \mathrm{~m}$ & $0.1-2 \mathrm{~m}$ & $30^{\circ} \pm 3^{\circ}$ & $0-1 \mathrm{k} \mathrm{Pa}$ & Swarm every 30 m \\
2 & $73^{\circ} \pm 5^{\circ}$ & $273^{\circ} \pm 10^{\circ}$ & $2-10 \mathrm{~m}$ & $0.5-2 \mathrm{~m}$ & $30^{\circ} \pm 3^{\circ}$ & $0-1 \mathrm{k} \mathrm{Pa}$ & $\begin{array}{l}\text { Swarm every 50- } \\
100 \mathrm{~m}\end{array}$ \\
3 & $65^{\circ} \pm 5^{\circ}$ & $62^{\circ} \pm 10^{\circ}$ & $10-20 \mathrm{~m}$ & $2-3 \mathrm{~m}$ & $30^{\circ} \pm 3^{\circ}$ & $0-1 \mathrm{k} \mathrm{Pa}$ & Swarm every $40 \mathrm{~m}$ \\
5 & $27^{\circ} \pm 5^{\circ}$ & $138^{\circ} \pm 10^{\circ}$ & $10-15 \mathrm{~m}$ & $1-5 \mathrm{~m}$ & $30^{\circ} \pm 3^{\circ}$ & $0-1 \mathrm{k} \mathrm{Pa}$ & Swarm every 40 m \\
6 & $43^{\circ} \pm 5^{\circ}$ & $98^{\circ} \pm 10^{\circ}$ & $1-3 \mathrm{~m}$ & $1-2 \mathrm{~m}$ & $30^{\circ} \pm 3^{\circ}$ & $0-1 \mathrm{k} \mathrm{Pa}$ & $\begin{array}{l}\text { Swarm every 50- } \\
100 \mathrm{~m}\end{array}$ \\
4 & $90^{\circ} \pm 15^{\circ}$ & $271^{\circ} \pm 5^{\circ}$ & $1-2 \mathrm{~m}$ & $<1 \mathrm{~m}$ & $30^{\circ} \pm 3^{\circ}$ & $0-1 \mathrm{k} \mathrm{Pa}$ & $\begin{array}{l}\text { Swarm every 50- } \\
100 \mathrm{~m}\end{array}$ \\
\hline
\end{tabular}

\subsection{Groundwater}

In the mine site area hypersaline groundwater (TDS $\sim 250,000 \mathrm{mg} / \mathrm{l}$ ) is contained in the two major aquifers, both of which have regional extent, namely the palaeochannel sand and gravel; and fractured bedrock. The palaeochannel aquifer occurs as local depressions or scour channels at the base of the superficial formations, above the contact with weathered Archaean bedrock. The superficial formations form a continuous cover over the Archaean bedrock, thickening towards the south. An infilled palaeodrainage trends from the northeast and east towards the west and southwest, traversing the southern extension of the Cleo pit. The basal sand and gravel deposits in the palaeochannel are generally only 2-6 m thick. The Archaean bedrock consists of a variety of rock types: intermediate and basic volcanics, volcaniclastic andesitic arenites, argillaceous sediments, banded iron formations, and intrusive veins and dykes of porphyry. The fractured bedrock aquifer is located mainly within the transition zone, and in the uppermost part of the fresh bedrock. Fracturing is associated with faults and shears (including the Sunrise Shear), veins and dykes, rock contacts and unconformities.

Both aquifers are vertically and laterally irregular, and are therefore anisotropic and inhomogeneous. The numerous drillholes in the area are believed to link permeable zones within the vertical profile. Original groundwater levels (pre-mining) were generally within $5 \mathrm{~m}$ of the ground surface. Water levels have been markedly lowered and flow directions altered since dewatering of the Sunrise pit began in late 1994. The groundwater regime is controlled principally by the regional paleochannel system of clayey, gravelly sands at the base of the transported sediments whose channels traverse the pit. Water is also present in perched water tables within the transported clays and within the weathered bedrock. The weathered bedrock aquifer is recharged by the paleochannel water table outside of the pit slopes. 
Throughout the existing underground water inflow has only occurred where drillholes from surface intersect workings. The effect of groundwater is assumed to be negligible in the initial model setup for the fresh rock. This assumption is currently being confirmed with the installation of porepressure piezometers in the underground, looking at the rock mass above, within and below the Sunrise Shear Zone (SSZ).

\subsection{Rock mass properties}

A number of strength testing programmes were completed to establish a rock mass property database consisting of UCS, modulus and joint shear strength data. The strength data base has been extended further through pointload testing conducted on exploration core and lump samples for each rock unit collected from selected blast blocks in the pit. Table 2 summarise the strength properties for the six main rock units found at Sunrise Dam.

Table 2 Rock unit strength properties

\begin{tabular}{ccccccc}
\hline Lithology & BIF & Dolerite & Mafic & Andesite & Volcanics & Porphyry \\
\hline Rock Code & ACI & AD & AB & AIA & AFS & AG \\
UCS $_{\text {Ave }}[\mathrm{MPa}]$ & 123 & 81 & 164 & 126 & 106 & 85 \\
$\mathrm{E}_{\mathrm{t}}[\mathrm{GPa}]$ & 67 & 47 & 75 & 40 & 65 & 92 \\
$v$ & 0.31 & 0.30 & 0.22 & 0.31 & 0.25 & 0.20 \\
GSI & 70 & 70 & 70 & 75 & 75 & 75 \\
\hline
\end{tabular}

Acoustic Emission (AE) and CSIRO Hollow Inclusion (HI-cell) stress tests have been completed as part of the underground feasibility study. A comparison of the results confirmed that similar to the region, higher horizontal stresses are expected. The formulae for the principal stresses obtained from the combined interpretations and currently used in numerical analysis are as follow:

$$
\begin{aligned}
& \sigma_{1}=0.072 \times \text { Depth }+9 \\
& \sigma_{2}=0.0487 \times \text { Depth }+5 \\
& \sigma_{3}=0.0292 \times \text { Depth }
\end{aligned}
$$

with trend and plunge of $155^{\circ} / 06^{\circ}$

with trend and plunge of $063^{\circ} / 20^{\circ}$

with trend and plunge of $260^{\circ} / 69^{\circ}$

Data collection is an ongoing process that facilitates the validation of the different geotechnical domains in each of the design sections.

\section{Developing the model}

A number of variants of rock and joint properties, and estimated in situ stresses, as described above, have been used to define the various domains on the selected design sections (Figure 3). This was done to provide insight into the range of pit slope behaviour that might be possible, given the uncertainty in the values of those parameters.

Properties used for treating the main rock units via the Hoek-Brown criterion was determined from the UCS, GSI, Young's Modulus, $\mathrm{m}_{\mathrm{i}}$, Poisson's ratio and Density data. Mohr-Coulomb parameters were specified for saprolites, other weathered materials and waste. Friction, cohesion, stiffness and tensile strength parameters were used for joints in the various rock units through the rock mass. Approximations to the sectional in situ stresses were made for each design section and groundwater pressures were taken as negligible.

All failure criteria data was now available to use in a numerical model. The failure mechanisms for the slope have been evaluated, and the one unknown was whether a quasi-circular step-path failure could occur, and 
what size this failure would be. A number of numerical codes are available to analyse instabilities in large slopes, but very few do a functional representation of failure along a combination of structural surfaces. It was decided to make use of the numerical programme UDEC specifically for its capacity to cater for structural discontinuities.

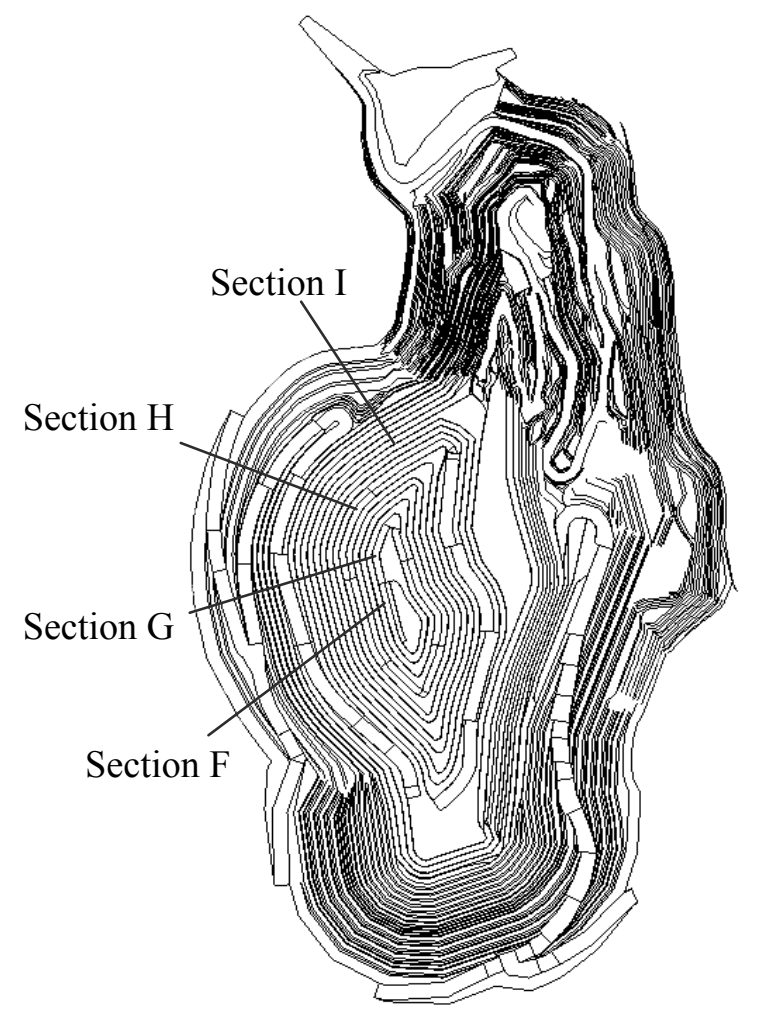

Figure 3 Design sections for the final west wall of Sunrise Dam

\subsection{Capabilities of the program}

$\mathrm{UDEC}^{1}$ (Itasca 2004) is a two-dimensional program, for analysis of slices through systems that are taken to be essentially infinite in extent and uniform (in geology, material properties, excavation boundaries and loadings) in the out-of-plane direction. It is a nonlinear stress analysis program, which as its acronym implies, was developed to treat slip and separation of blocks within jointed rock masses.

UDEC can also represent yield within the rock material of blocks. It is therefore equally well suited to analysis of systems containing a number of isolated structural discontinuities.

In addition, the program can:

- Simulate the effects of rock support mechanics, via various structural elements that interact with the rock blocks.

- Perform effective stress analyses, based on assumed distributions of water pressure within the rock material and/or in joints.

- Model transient fluid flow - via laminar flow along joints, but not porous flow through rock material, either by itself or fully coupled with stress analysis.

- Have additional features added by the user, using the in-built programming language, FISH.

Like most other stress analysis programs, it can in principle be used in two broad ways:

1. Given detailed and accurate input data, to perform precise computations and make firm predictions regarding the response of a system such as an open pit. 
2. Given qualitative or uncertain data on the properties and distributions of different rock units and joints, and in situ conditions, to undertake parametric studies of a system. This can lead to an understanding of the likely range of behaviour and of mechanisms of failure that might develop (and that therefore might need to be guarded against via rock support, changing the excavation sequence, etc.).

It should also be noted here that the key to 'type 2' modelling is to ensure that physically possible mechanisms are not precluded by the way in which a numerical model is set up. For instance, if slip on a major fault might be an important factor in determining stability of a slope, there is no point in analysing that slope using a program that assumes that the rock mass behaves as a continuum.

\subsection{Explicit finite difference method}

The explicit finite difference method (FDM) for solving problems in nonlinear mechanics, which underlies UDEC, is based on numerical time-stepping of the equations of motion for a discretised system representing the rock mass. This should be contrasted with most finite element and boundary element methods of stress analysis, which are based on equations of (assumed) equilibrium for the system. Because the FDM does not begin by assuming that the system is in equilibrium, it does not break down numerically if the system is loaded to a point where a failure begins to develop. This makes these programs very powerful for use in geomechanics, where dealing with potential failures is a necessary fact of engineering life. However, as discussed in the next section, that advantage is balanced by the fact that the user must take greater care to adopt a modelling strategy that will produce physically realistic results.

\subsection{Capabilities of the program}

Some of the issues that need to be kept in mind when using UDEC include:

The program is designed for nonlinear stress analyses, with plastic yield within rock material (in shear and in tension), slip and separation on joints, and large strains and displacements. The final state of any nonlinear system can depend strongly on the stress path by which it reaches that state. It is therefore critical that analyses with the program are set up so that the numerical model is subjected to a stress path that reflects as closely as possible that for the real system.

The explicit finite difference method allows fully dynamic analyses to be performed for systems with timevarying loads, but quasi-static analyses can also be performed when loads (or unloadings, for the case of excavations) vary slowly with time. The latter are still based on integration of the equations of motion, but with artificial damping applied as part of the numerical solution process to make the system respond in a quasi-static manner. In such cases, the sudden changes in applied loads within the model when an excavation is created or extended will induce transient stress waves. As these are not 'real', the modeller must ensure that they do not cause physically inappropriate yield to occur anywhere within the system. This is particularly important with jointed systems, where transient tensile stress waves crossing a joint may make it open and close almost instantaneously, thereby 'losing' its shear stress and perhaps dropping it to residual strength.

Each stage of an analysis must be 'stepped' long enough for the system to come to equilibrium, if indeed that is to be the computed final state. Alternatively, if a localised or extensive failure is predicted to occur, the user needs to ensure that the numerical solution proceeds long enough to demonstrate the mechanism and extent of any failure, but not continue unnecessarily with the analysis beyond that point.

Geomechanics invariably deals with effectively semi-infinite rock masses. A numerical model must be truncated at some point, and boundary conditions applied there to simulate the far-field rock response. The user must ensure that these artificial boundaries are sufficiently far from the region of interest that they do not significantly influence the computed response.

UDEC is a 2D code, which clearly will never be strictly appropriate for a real system. An engineer assessing the modelling must determine whether this might unduly influence the results, and then decide whether a 3D analysis (for instance, with the companion program 3DEC) might be necessary for a full understanding of the system's behaviour. 
However, a 2D model very often represents a worst-case approximation of a real slope, because the beneficial horizontal 'arching' around the periphery of the pit is neglected. Unless the real mechanism of failure involves 3D wedges that are not simulated in the 2D model, it is likely that a 3D model would predict that the pit is more stable than 2D models indicate.

\subsection{Sunrise Dam models}

The consequences of these general issues, for the strategies employed for the specific SDGM models that have been run, include the following:

Each model was set up to consist of several computational stages (Figure 4):

0 . Equilibration of in situ stresses, prior to any mining.

1. Excavation of stage 1 of pit.

2. Excavation of stage 2 of pit.

3. Excavation to final open pit (and placement of waste dump for all except Section 1).

To ensure that the pre-mining stress field in the model matched as closely as possible the best knowledge of the actual in situ stresses, the above $0^{\text {th }}$ stage of modelling proceeded as follows:

- All rock units and geological structures were set up (Figure 5), with properties assigned, and with gravity loading acting on the model section.

- An initial estimate of the stress field was set in the model, based on the available data. In some cases vertical stress was computed in terms of an approximate average density; then in-plane and out-ofplane horizontal stresses from specified $\mathrm{K}_{\mathrm{o}}$ values. In other cases, in-plane principal stresses were rotated via inclusion of specified shear stress terms.

- The system was brought to equilibrium. When this is complete, the vertical stress will be zero at the free surface, and its variation with depth will reflect the variation of density throughout the region. This adjustment of vertical stresses will also alter the horizontal and shear stresses, but it will lead to a consistent set of equilibrium stresses that can be used as a starting point for the analysis of mining.

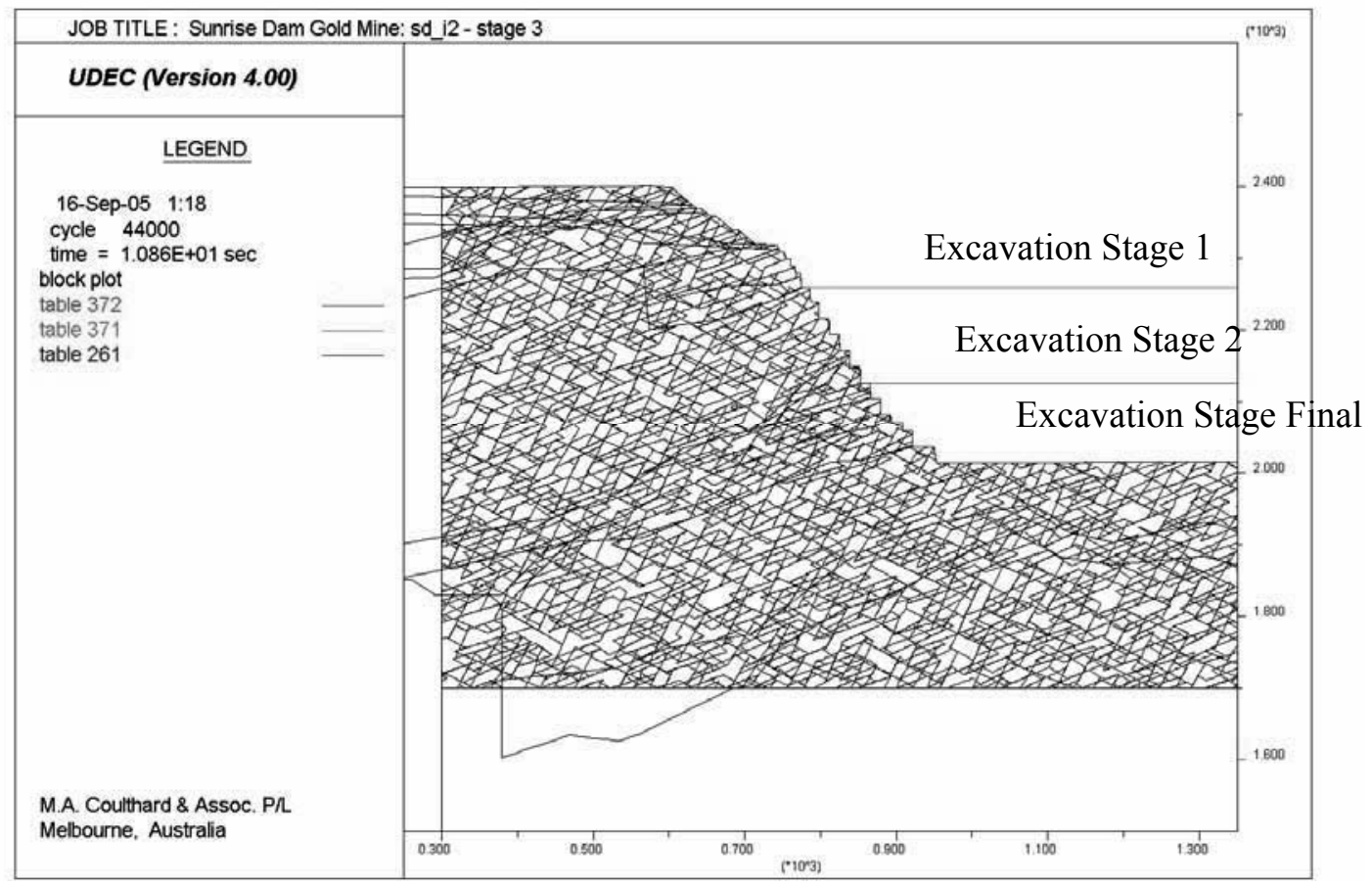

Figure 4 Computational stages for the model 


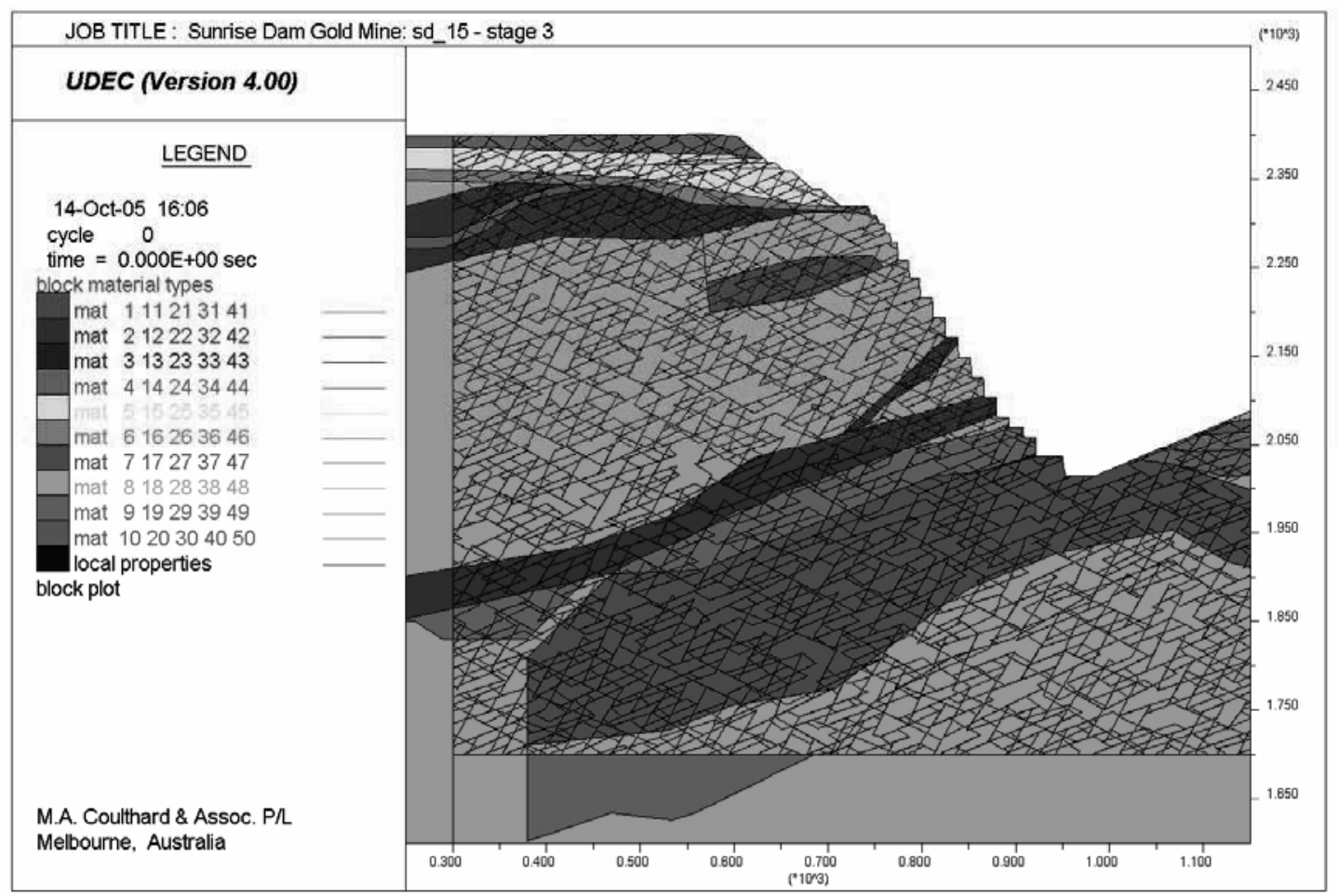

\section{Figure 5 Rock units and geological structures for the model}

Each stage in the analysis actually consisted of two sub-stages:

- System was stepped close to equilibrium, with all rock and joint strengths increased, to avoid physically spurious yield of rock or joints during the numerical damping of stress waves that inevitably arise in the model when loadings are suddenly changed.

- Strengths were returned to 'real' values, then system was again stepped to equilibrium, or until a failure mechanism clearly developed.

The results were examined for each stage of the analysis, to determine whether any failure mechanisms were developing. These can be seen via plots of plastic state (which show rock regions of active shear or tensile yield, as well as those regions where yield has occurred in the past) and joint slip / separation, and plots of velocity vectors or components. A failure mechanism can be formed by active shear or tensile yield through intact rock material and/or by slip/separation on joints or shears.

In addition, stability of the final pit walls has been assessed in many of these models. One possible approach is to use a new 'solve fos' command that had been added to UDEC version 4.0 to facilitate the computation of factors of safety (FoS) and of failure mechanisms. However, some implausible results were obtained in our early tests of this command. Investigation revealed that the automated procedure in UDEC, with default search parameters, was missing the critical transition from stable to unstable slopes in some cases, and so was over-predicting the FoS, i.e. was producing non-conservative results. More reliable and consistent results have since been obtained by setting much tighter search criteria, but this can extend run times greatly.

Alternatively, strengths of all rock units and block interfaces may be progressively reduced semi-manually, using FISH routines developed some years ago by one of the authors (M. Coulthard), then the FoS is estimated by observing the response of the slopes as those strengths were changed. The strength reduction factor (SRF) at the point at which a failure initiates gives an upper limit to the FoS for that part of the system. This approach has been used in most of the analyses reported here. 


\subsection{Rock constitutive models}

The strength of the various rock units is represented using the Hoek-Brown criterion. Hoek-Brown response has been simulated in UDEC via the in-built Mohr-Coulomb model, using FISH code that was originally developed for FLAC and UDEC pit slope analyses at Ok Tedi mine (Coulthard, 1999). These routines have been applied to other mine slopes, and have been updated to use the 2002 form of Hoek-Brown (Hoek et al, 2002). As confining stresses reduce towards the free surface, the concave-down shape of the Hoek-Brown curve means that the cohesions equivalent to the tangent to Hoek-Brown progressively reduce and friction angles increase. These are updated regularly during the course of the analysis, to ensure that the effective strength parameters are always closely consistent with the intended Hoek-Brown envelope. The upper strata and waste dump material have been represented using the standard Mohr-Coulomb model in UDEC.

\section{$4 \quad$ Results}

A variety of failure mechanisms were predicted by the UDEC models and can be described as follow:

- Local 'circular slip' forms in weathered material in the upper slope.

- Failures of parts of the central region of the slope that were governed by slip and/or separation on joints.

- Composite failures affecting a major part of the slope.

FoS values ranged from about 1.1 to 1.3 , depending on the particular section and parametric variations (Coulthard, 2007).

Figures 6 to 9 depicts the mechanism of failure for open of the models runs for Section I (model sd_i15) with strength reduction factor $=1.10$.

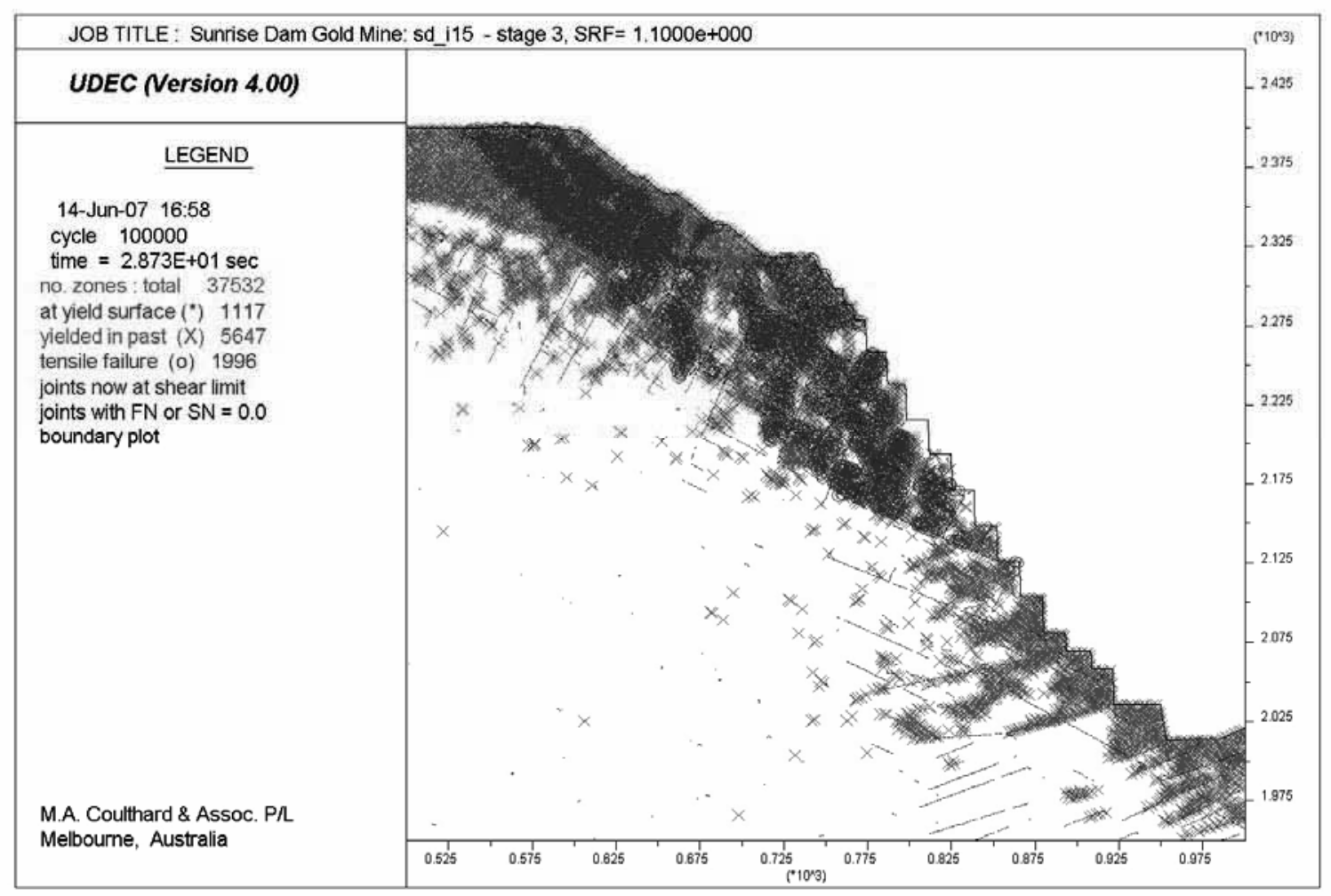

Figure 6 Plastic state and slip/separation on joints shows shear through upper strata and active tensile yield within blocks in rock slope 


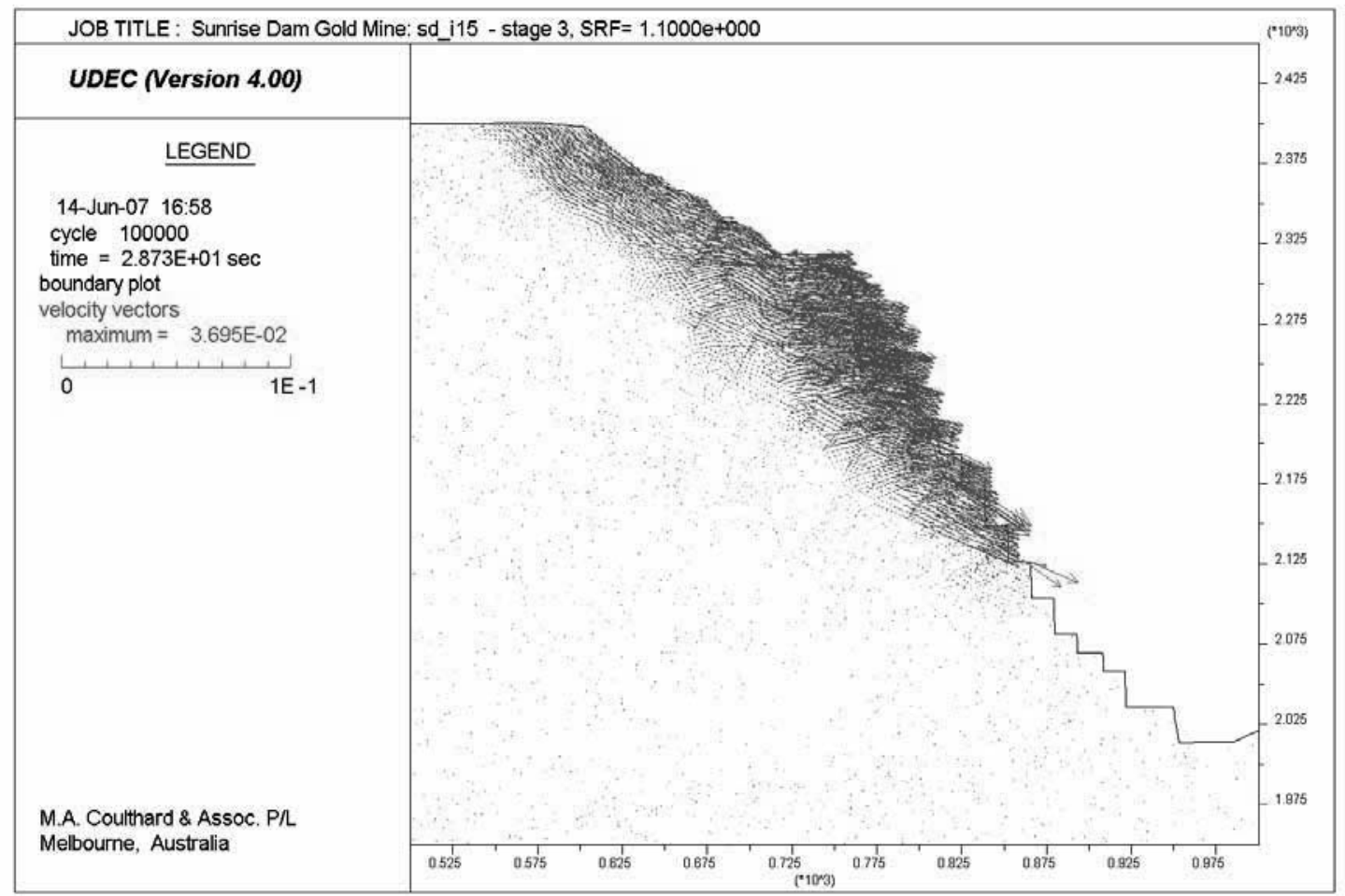

Figure 7 Velocity vectors indicate extent of developing failure

\begin{tabular}{|c|c|c|}
\hline \multicolumn{2}{|c|}{ JOB TITLE : Sunrise Dam Gold Mine: sd_i15 - stage 3, SRF $=1.1000 \mathrm{e}+000$} & \multirow{2}{*}{$\begin{array}{l}(1003) \\
-2425\end{array}$} \\
\hline UDEC (Version 4.00) & & \\
\hline \multirow{2}{*}{$\begin{array}{l}\text { LEGEND } \\
\text { 14-Jun-07 } 16: 58 \\
\text { cycle } 100000 \\
\text { time }=2.873 \mathrm{E}+01 \mathrm{sec} \\
\text { X velocity contours } \\
\text { contour interval= } 2.000 \mathrm{E}-03 \\
2.000 \mathrm{E}-03 \text { to } 2.200 \mathrm{E}-02\end{array}$} & & -2375 \\
\hline & & $\begin{array}{l}-2325 \\
-2275\end{array}$ \\
\hline $2.000 \mathrm{E}-03$ & & 2225 \\
\hline $\begin{array}{l}4.000 \mathrm{E}-03 \\
6.000 \mathrm{E}-03\end{array}$ & & \\
\hline 8.000E-03 & & 2175 \\
\hline $1.200 \mathrm{E}-02$ & & \\
\hline $\begin{array}{r}1.400 \mathrm{E}-02 \\
1.600 \mathrm{E}-02 \\
\end{array}$ & & -2.125 \\
\hline $1.800 E-02$ & & \\
\hline $2.200 E-02$ & & -2.075 \\
\hline block plot & & \\
\hline $\begin{array}{l}\text { M.A. Coulthard \& Assoc. P/ } \\
\text { Melbourne, Australia }\end{array}$ & & \\
\hline & & \\
\hline
\end{tabular}

Figure 8 Contours of $x$-velocity show failure is more intense in central slope but extends to surface 


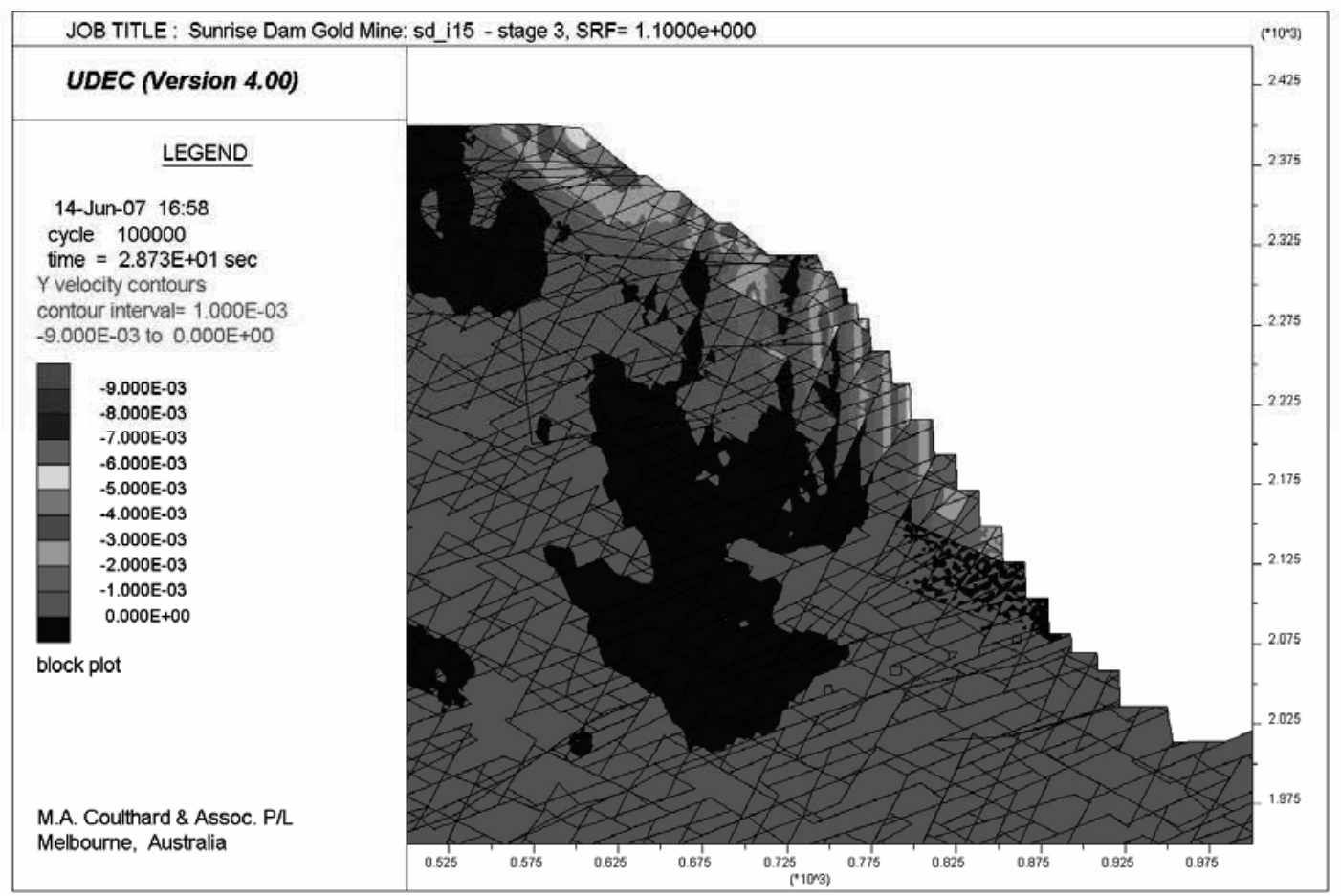

Figure 9 Contours of y-velocity confirm mechanism and show how its details relate to jointing

The results of this first set of parametric studies now forms the basis from which slope monitoring, data validation and future numerical analysis are conducted.

\section{Conclusions}

The numerical analysis confirmed that the slope design angles (Table 3) used for the west wall slopes are stable for the rock mass properties selected for each geotechnical domain as defined by the different rock units.

Analyses were also completed with minimum and maximum values for the joint and rock mass properties using Rosenblueth's point estimation method to calculate a probability of failure for the main trial design section, Section 1.

The UDEC numerical models have been set up so that altering the geotechnical domain properties and boundaries can be done easily, to rerun a model where new slope validation mapping and performance monitoring data have become available. This will facilitate the next step, which is to calibrate the model with monitoring data, and update the geotechnical domains with the new face mapping data if required.

Table 3 Slope angles for Sunrise Dam open pit

\begin{tabular}{lcc}
\hline & Weathered & Fresh \\
\hline Overall slope angle & $25-35^{\circ}$ & $30-53^{\circ}$ \\
Inter-ramp angle & $30-45^{\circ}$ & $45-59^{\circ}$ \\
Batter angle & $50-65^{\circ}$ & $90^{\circ}$ \\
\hline
\end{tabular}

Similar to a block model for an orebody, a numerical model for a slope must be validated with the latest structural data and geotechnical domain descriptions and rerun. The frequency of such updates will depend on the rate of descent, where a new geotechnical domain has been defined, when changes occur in rock mass properties, when movement has been detected, with changes in groundwater pressures or levels, or with a change in slope geometry. 
During the slope formation process the mined slope will contain the actual structures. Understanding these structures, how they formed, their properties and how they could impact the final slope rock mass is vital to construct a representative numerical model and not just a random distribution of joints.

\section{Acknowledgements}

The authors wish to recognise the commitment of Chris Fowers who have developed the structural models for Sunrise Dam Gold Mine. And a special thanks to Jo for being so patient.

The authors also wish to thank AngloGold Ashanti Australia for granting permission for this paper to be published.

\section{References}

Coulthard, M.A. and Little, T.N. (1999) Modelling of stability of high westwall at Ok Tedi Copper-Gold Mine. pp. 3946, Proceedings for International Symposium on FLAC and Numerical Modelling in Geomechanics, Minneapolis, USA. C. Detournay \& R. Hart (eds.) Rotterdam: Balkema.

Coulthard, M.A. (2007) UDEC stress analysis models of Section F,G,H and I at Sunrise Dam Gold Mine, Unpublished report, February 2007.

Hoek, E., Carranza-Torres, C. and Corkum, B. (2002) Hoek-Brown Criterion - 2002 edition. Proc. NARMS-TAC 'Mining and Tunnelling Innovation and Opportunity', Toronto, Canada. University of Toronto Press, pp. 267273.

ITASCA. UDEC - Universal Distinct Element Code, Version 4.0, User Manual. Itasca Consulting Group, Inc., Minneapolis, Minnesota, U.S.A., 2004.

Lilly, P.A. (2002) Open pit mine slope engineering: a 2002 perspective. Western Australian School of Mines, Curtin University of Technology.

Fowers, C. (2005) Geotechnical structural modelling: East wall project. Internal report, June 2005 (unpublished).

Fowers, C (2006) Geotechnical structural modelling: West wall project. Internal report, March 2006 (unpublished). 